\title{
Research on Torque Ripple Reductions for Switched Reluctance Motor
}

\author{
Diao Tongshan* \\ School of Electrical Engineering and Automation, \\ Qilu University of Technology, \\ Jinan, China \\ E-mail: diao-tong-shan@126.com \\ * Corresponding Author
}

\begin{abstract}
The inhibition of noise and vibration on switched reluctance motor (SRM) was study in this paper to improve the speed regulation system. Nonlinear dynamic simulation model based on the SRM is studied based on torque estimation method of torque ripple. Time-varying and nonlinear characteristics of SR motor, speed controller for closed-loop system using a fuzzy PID controller for speed adjust, the simulation results show that the system has good torque ripple effect.
\end{abstract}

Keywords-switched reluctance motor; torque ripple; fuzzy PID controller; simulation; noise and vibration

\section{INTRODUCTION}

Similar to the variable reluctance stepping motor, the switched reluctance motor (SRM) belongs to a doubly salient and singly-excited machine [1-3]. It possesses a lot of inherent structural advantages, such as rigid structure, high power density, high reliability, low maintenance requirement and suited for high-temperature and highspeed operations. In addition, its converter is free from arm fed through short circuit. However, the SRM also suffers from many disadvantages: (i) high torque ripple; (ii) high acoustic noise and vibration; (iii) absolute rotor position information is required for performing the converter switching for the SRM; (iv) nonlinear winding inductance and torque generating characteristics[2-10].

Although there are many inherent structural advantages, the doubly-salient structure and non-ideal switched square wave winding current give the SRM higher torque ripple, and thus lead to the generation of higher vibration and acoustic noise. In addition, the rotor position and current dependent winding nonlinear inductance makes its torque and dynamic behaviour highly nonlinear. Moreover,analysis of vibration behaviour is also difficult to perform accurately. For performing the development of key technologies, it is indispensable to understand thoroughly the key features of an SRM. In this Section, the governing equations of an SRM are first introduced, and then the sources of vibration and acoustic noise are considered[11-18].

This paper seeks to improve the performances for SRD based on studying its vibration and acoustic noise. The paper is organized as follows. Section II depicts the design of torque measurement and torque regulator. In Section III, effect of torque measurement.Simulation results on $22 \mathrm{~kW}$ LSPM are provided, In Section IV, the fuzzy PID controller was designed.In Section V simulation results based on torque observation was got,and finally, conclusions are drawn in Section VI.Simulation studies are carried out to verify the proposed method.

\section{DESIGN OF TORQUE MEASUREMENT AND TORQUE REGULATOR}

Torque observation link design is based on the measured SR motor rotor position angle and current value to calculate the current phase of the torque, according to the torque deviation to adjust, get the desired torque. The torque regulator is used to calculate the desired current by the desired torque. According to the torque angle characteristic of SR motor, the current expectation value of different torque is calculated by the torque as the independent variable. The simulation structure of the observation and torque regulator is shown in Fig.1.

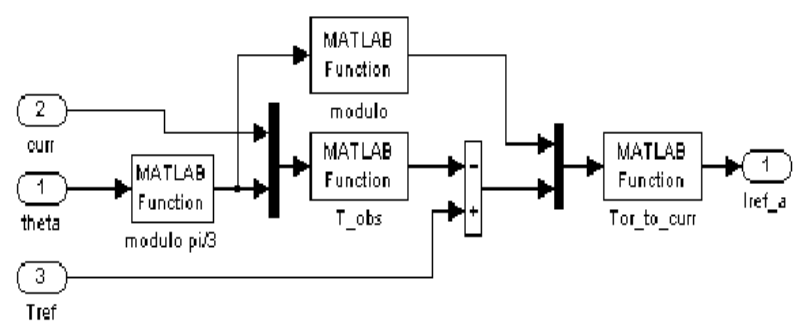

Figure 1. Simulation structure of torque observation link

\section{EFFECT OF TORQUE MEASUREMENT}

The winding of the SR motor requires only a single direction of current, but it should be able to receive power from the power supply quickly, and can quickly return to the power supply. Therefore, SRM power converter need only provide a single direction of current to the SR motor, due to the inductive energy storage role, in the stop on the winding power supply also need of the phase provides a freewheeling loop. In the process of continuous flow, the current direction of the winding is constant, and the position of the rotor is still in the region of the positive torque. Because the algorithm uses the PWM single phase control mode, in the current phase of the torque control, should consider the first phase winding continued to flow generated electromagnetic torque[12-18].

\section{A. Current regulator design}

The current regulator is composed of a current hysteresis loop, which is based on the deviation between the given current and the actual current, and controls the opening and closing of the switch tube of the power converter to change the output voltage polarity. The 
current regulator adjusting, actual current will focus on a given current jagged changes and the deviation is limited within the specified error range, to ensure the actual current tracking current are given, the realization of SRM current chopping control.

\section{B. Speed regulator design}

In the speed loop, the speed regulator is derived from the reference torque value according to the deviation of the set speed $w$ ref and the feedback speed $w$.Nonlinear dynamic simulation model of SRM based on simulink is shown in Fig.2.

Mechanical equation of switched reluctance motor

$$
T_{e}=J \frac{d^{2} \theta}{d t^{2}}+F \frac{d \theta}{d t}+T_{L}
$$

where, $\mathrm{T}_{\mathrm{e}}, T_{I}, F, \theta$ is the electromagnetic torque,the load torque, the damping coefficient, the rotor position angle, respectively.

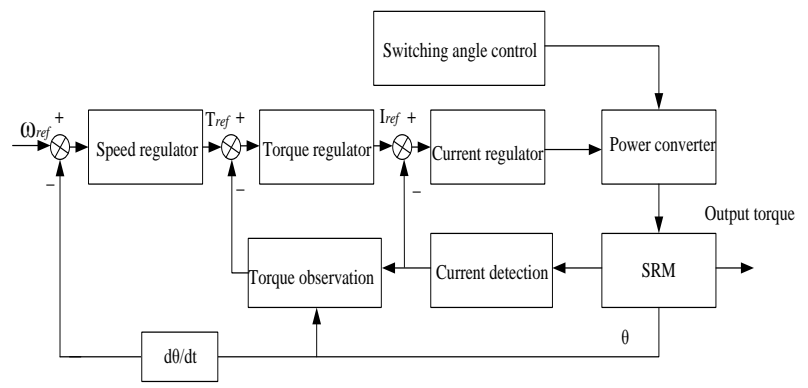

Figure 2. Nonlinear dynamic simulation model of SRM based on simulink

Angular velocity equation of switched reluctance motor

$$
\omega=\frac{d \theta}{d t}
$$

Where $\omega$ is angular velocity.

From (1) and (2),we can get

$$
J \frac{d \omega}{d t}=T_{e}-F \omega-T_{L}
$$

When SRM is stable,

$$
\frac{d \omega}{d t}=0
$$

From (2),we can get

$$
\square T_{e}=J \frac{d \omega}{d t}
$$

Where $d \omega \approx \square \omega, d t \approx \square t$

$T_{e}=F \omega+T_{L}$

$$
\underset{\text { where }}{\square T_{e}=\frac{J \square \omega}{\square t}}
$$

$$
K_{p}=\frac{J}{\square t} \square T_{e}=K_{p} \square \omega
$$

By the formula (6), the deviation of the electromagnetic torque is proportional to the deviation of the rotational speed, so that the deviation of the speed can be converted into a torque deviation by a proportional regulator. In actual control, in order to eliminate the steady-state error of the system and need to introduce the integrating factor, while the introduction of differential link conditioning system dynamic process, in order to make the system has good dynamic and static performance, so the speed regulator with PID controller. The conventional PID controller is a linear regulator, which is stable and reliable, and has some limitations on the ability to adjust the nonlinear control object. In this paper, we study the SRM is a time-varying, nonlinear system, if the use of conventional PID controller, the performance is not satisfactory, so this paper uses adaptive fuzzy PID controller[19-22].

\section{DESIGN OF FUZZY PID CONTROLLER}

In this paper, the fuzzy PID controller is used to modify the PID parameters online by using the fuzzy control rules, as the input of the $\mathrm{EC}$ and the deviation change rate of E. The structure of fuzzy PID controller based on SIMULINK simulation environment is shown Fig.3. Deviation E and deviation change rate EC absolute value and scaling limit to theory within the domain of fuzzy reasoning, three parameters are obtained after into PID controller, respectively is multiplied by the deviation, the deviation of the integral and error differential get the total amount of control, namely the reference torque.

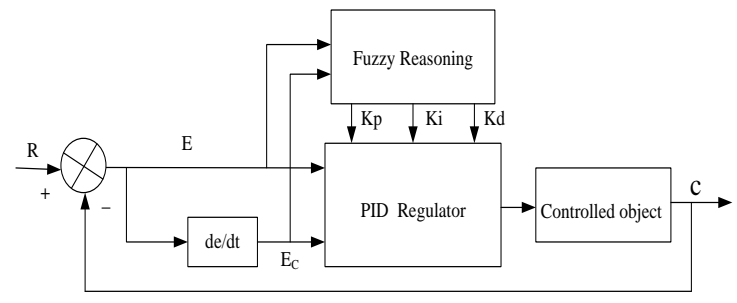

Figure 3. Fuzzy PID controller structure diagram

The stability, response speed, overshoot and steady state accuracy of the system are considered. The parameters of $\mathrm{K}_{\mathrm{p}}, \mathrm{K}_{\mathrm{I}}$ and $\mathrm{K}_{\mathrm{D}}$ are as follows:

Proportional coefficient $K_{P}$ 's role is to speed up the response speed of the system, improve system accuracy. $\mathrm{K}_{\mathrm{P}}$ is bigger, faster system response speed, the higher the accuracy of the system, namely the higher the resolution of deviation, but overshoot, and even lead to system instability. $K_{p}$ value is too small, you will reduce the accuracy, especially for slow response, thus prolonging the settling time, to bad the static and dynamic characteristics of the system.

The integral action coefficient $\mathrm{K}_{\mathrm{I}}$, the function is to eliminate the system's steady state error. $\mathrm{K}_{\mathrm{I}}$, the more large, the static error of the system is eliminated, but the $\mathrm{K}_{\mathrm{I}}$ is too large. In the initial stage of the response process, the integral saturation phenomenon will be generated, which 
will lead to a large response. If $\mathrm{K}_{\mathrm{I}}$ is too small, will make the system static error is difficult to eliminate, the impact of the system's accuracy.

The function of differential coefficient $K_{D}$ is to improve the dynamic performance of the system. Because the PID controller of the differential role link is the response of the system deviation change rate EC and its role is mainly in response to suppress the deviation in any direction changes, the deviation changes were predicted in advance. However, the $\mathrm{K}_{\mathrm{D}}$ is too large, it will make the response process too early to brake, so as to extend the adjustment time, and the system's anti-interference performance is poor.

The tuning of the PID parameter must take into account the differences in the effects of the three parameters at different times and the relationship between them. According to the influence of the parameters $K_{P}, K_{I}$, and $\mathrm{K}_{\mathrm{D}}$ on the output characteristics of the system, the system can be summarized in the general situation. For different $|E|$ and $|E C|$, the controlled process parameters $\mathrm{K}_{\mathrm{P}}, \mathrm{K}_{\mathrm{I}}$, and $\mathrm{K}_{\mathrm{D}}$. Self tuning requirements for:

(1)When $|E|$ is large, the system is in the I section of the response curve, in order to speed up the system response speed, and avoid the deviation of the $\mathrm{E}$ of the moment become large at the beginning of, may cause differential over saturation, and make the control effect beyond the license range, therefore, the larger $K_{P}$ and smaller $\mathrm{K}_{\mathrm{I}}$, in order to make the system response speed up, and to prevent to integral saturation, to avoid the system to respond to a larger overshoot, this time should be removed from the integral role, take $\mathrm{K}_{\mathrm{I}}=0$;

(2) when $|E|$ and $|E C|$ are of medium size, the system is in the II section of the response curve, $K_{P}, K_{I}$ and $K_{D}$ can not take large, should take the smaller $\mathrm{K}_{\mathrm{I}}, \mathrm{K}_{\mathrm{P}}$ and $\mathrm{K}_{\mathrm{D}}$ value of the size to be moderate, in order to protect response speed of card system;

TABLE 1 FUZZY RULE TABLE OF $K_{\mathrm{P}}$

\begin{tabular}{|c|c|c|c|}
\hline$|E|$ & $\mathrm{B}$ & $\mathrm{M}$ & $\mathrm{S}$ \\
$\mathrm{Kp}$ & & & \\
\hline$|E C|$ & & & \\
\hline $\mathrm{B}$ & $\mathrm{S}$ & $\mathrm{S}$ & $\mathrm{S}$ \\
\hline $\mathrm{M}$ & $\mathrm{M}$ & $\mathrm{M}$ & $\mathrm{M}$ \\
\hline $\mathrm{S}$ & $\mathrm{B}$ & $\mathrm{B}$ & $\mathrm{B}$ \\
\hline & & & \\
\hline
\end{tabular}

(3)When $|E|$ is small, the system is in the III section of the response curve, so that the system has good steady state performance.Take larger $\mathrm{K}_{\mathrm{P}}$ and $\mathrm{K}_{\mathrm{I}}$, while avoiding the system to avoid the oscillation in the vicinity of the system, and consider the system anti-jamming performance, the value of $\mathrm{K}_{\mathrm{D}}$ should be appropriate, the principle is: when $|E C|$ is less value than that of $\mathrm{K}_{\mathrm{D}}$.It is usually taken as medium size; when $|E C|$ is large, $\mathrm{K}_{\mathrm{D}}$ should be smaller.

The parameters of, and $\mathrm{K}_{\mathrm{p}}$ are obtained by Mmadani, and the $K_{I}$ and $K_{D}$ are used to solve the fuzzy, and the input and output parameters of the graph are shown in TABLE I, TABLE II and TABLE III .

TABLE 2.FUZZY RULE TABLE OF $K_{I}$

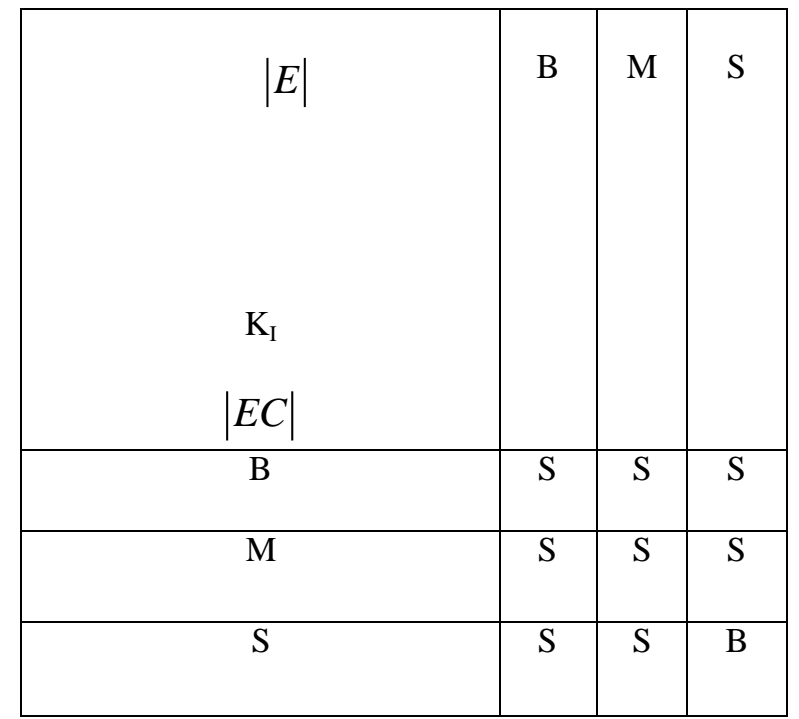

TABLE 3 FUZZY RULE TABLE OF $K_{D}$

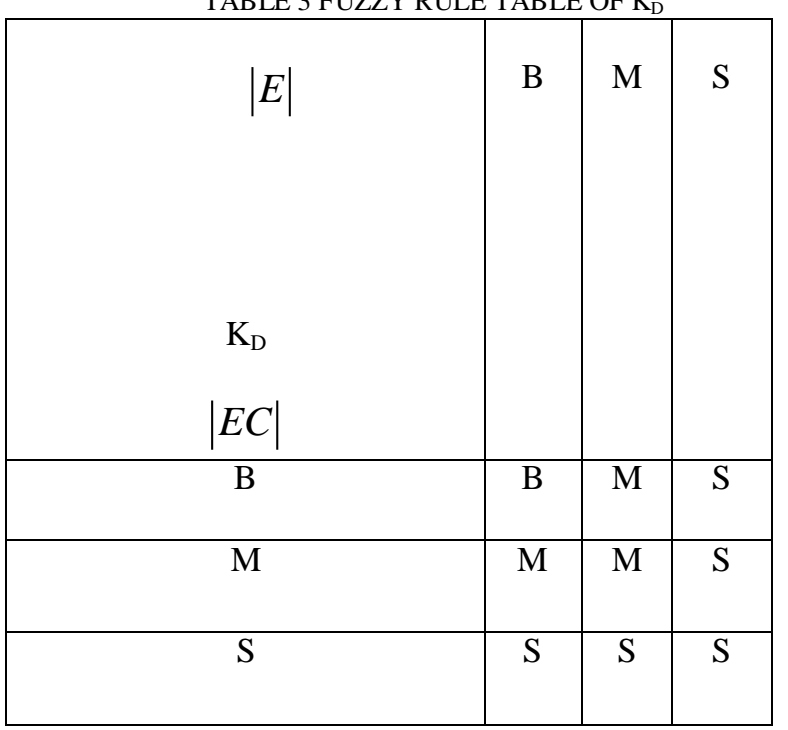

In Fig.4(a)and(b) is membership function diagram of $|E C|$ and $|E|$,respectively. 


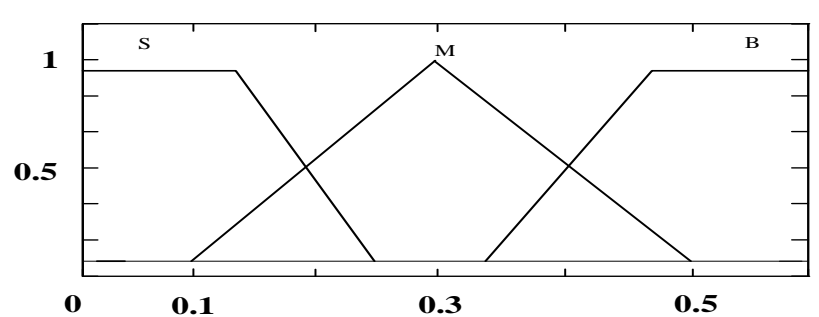

(a)

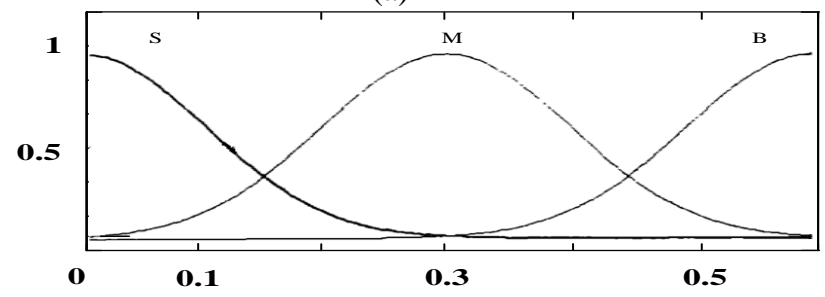

(b)

Figure 5. $K_{p}, K_{i}$ and $K_{d}$ membership function diagram

\section{SimUlation RESULTS BASED ON TORQUE OBSERVATION}

The nonlinear dynamic simulation model of the prototype waveforms of plus torque observation link corresponding each phase torque, torque and speed, corresponding to the Fig.5 is without torque observation link the torque phase, the total torque and speed simulation waveform. The comparison between the 4 and the 5 and the shows that the torque and the torque ripple can be reduced and the speed fluctuation can be reduced.

Fig.6 is contrast wave if not torque observation link corresponding total torque and rotational speed of the simulation waveform. Contrast Fig.6 and Fig.7, join the torque observation link, can reduce the torque and total torque pulsation, decrease the speed fluctuation.

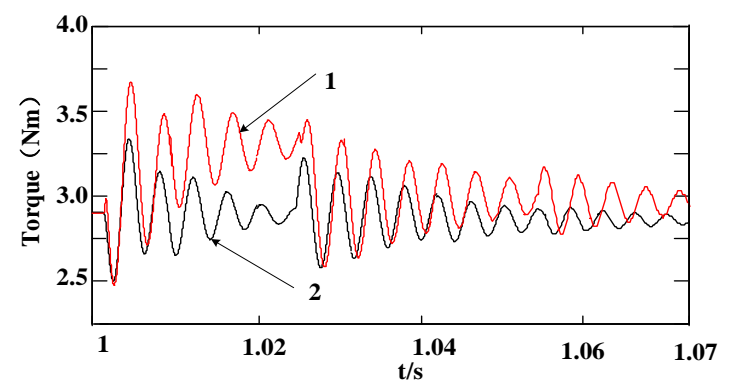

1-not torque observation 2-torque observation Figure 6.Torque observation of system performance

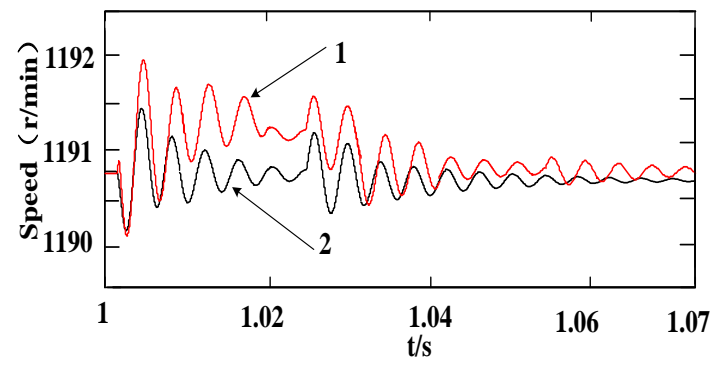

1-not torque observation 2-torque observation Figure 7.Speed observation of system performance
Fig.6 is the torque loop for the fuzzy PID controller of the torque simulation waveform. The relevant parameters in the simulation are as follows: $\theta_{\text {on }}=4^{\circ}, \theta_{\text {off }}=25^{\circ}$, voltage $\mathrm{U}=110 \mathrm{~V}$. Fig. 6 is a given speed $1191 \mathrm{r} / \mathrm{min}$ when moment of inertia is $000183 \mathrm{~kg} . \mathrm{m}^{2}$ for speed waveform, we can see from the graph, for a given speed, adjust the parameters of fuzzy PID can effectively restrain the fluctuation of torque.

Fig.7 is the speed loop for the fuzzy PID controller of the speed simulation waveform. The relevant parameters in the simulation are as follows: $\theta_{\text {on }}=4^{\circ}, \theta_{\text {off }}=25^{\circ}$, voltage $\mathrm{U}=110 \mathrm{~V}$. Fig. 7 is a given speed $1191 \mathrm{r} / \mathrm{min}$ when moment of inertia is $000183 \mathrm{~kg} \cdot \mathrm{m}^{2}$ for speed waveform, we can see from the graph, for a given speed, adjust the parameters of fuzzy PID can effectively restrain the fluctuation of speed, speed and stable operation of a $1191 \mathrm{r} / \mathrm{min}$.

Thus, a fuzzy PID controller adjusting ability, excellent control performance and system parameters change, it can effective regulation and control, for SRD the time-varying, nonlinear and complex system, a fuzzy PID controller can obtain good system dynamic and static performance to achieve reliable speed.

\section{CONCLUSIONS}

The nonlinear dynamic simulation model of SRD based on of suppression in SRD based on torque observation method of torque ripple, in view of switched reluctance motor (SRM) is a time variable, nonlinear characteristics, the speed of the closed-loop system regulator, a fuzzy PID controller in speed regulation. The simulation results show that the system has good torque ripple suppression effect.

\section{REFERENCES}

[1] SAHRAOUI H., ZEROUG H., TOLIYAT H.A."Switched reluctancemotor design using neural-network method with static finite-element simulation," IEEE Trans. Magn., 2007, 43,(12), pp. 4089-4095

[2] NABETA S.I., CHABU I.E., LEBENSZTAJN L., CORREA D.A.P., DA SILVAW.M.,HAMEYER K."Mitigation of the torque ripple of a switched reluctance motor through a multiobjective optimization,'IEEE Trans. Magn., 2008, 44, (6), pp. 1018-1021

[3] CHOI Y.K., YOON H.S., KOH C.S."Pole-shape optimization of a switched-reluctance motor for torque ripple reduction," IEEE Trans. Magn., 2007, 43, (4), pp. 1797-1800

[4] SHETH N.K., RAJAGOPAL K.R. “Optimum pole arcs for a switched reluctance motor for higher torque with reduced ripple," IEEE Trans. Magn., 2003, 39, (5), pp. 3214-3216

[5] CHOI J.H., AHN J.S., LEE J.“The characteristic analysis of switched reluctance motor considering DC-link voltage ripple on hard and soft chopping modes," IEEE Trans.Magn., 2005, 41, (10), pp. 4096-4098

[6]CHAI J.Y., LIAW C.M."Robust control of switch-mode rectifier considering nonlinear behavior," IET Electr. Power Appl., 2007, 1, (3), pp. 316-328

[7] HWU K.I., LIAW C.M."Intelligent tuning of commutation for maximum torque capability of a switched reluctance motor," IEEE Trans. Energy Convers., 2003, 18, (1),pp. 113-120

[8] SHAKED N.T., RABINOVICI R."New procedures for minimizing the torque ripple in switched reluctance motors by optimizing the phase-current profile," IEEE Trans. Magn.,2005, 41, (3), pp. 1184 1192

[9]SAHOO S.K., PANDA S.K., XU J.X."Indirect torque control of switched reluctance motors using iterative learning control," IEEE Trans. Power Electron., 2005, 20, (1),pp. 200-208

[10] Panda D, Ramanarayanan V. "Reduced acoustic noise variable DC-bus-voltage-based sensorless switched reluctance motor drive for HVAC applications." IEEE Trans. Industry Electronics, 2007, 54(4): 2065-2078. 
[11] Rasmussen P O, Andreasen J H, Pijanowski J M. "Structure stator spacers-a solution for noise reduction of switched reluctance motors," IEEE Trans. Industry Applications, 2004, 40(2): 574-581.

[12] Chai J Y, Liaw C M. "Reduction of speed ripple and vibration for switched reluctance motor drive via intelligent current profiling, " IET Proc. Electr. Power Appl. , 2010, 4(5): 380-396.

[13] Ahn J, Park S, Lee D. "Hybrid excitation of SRM for reduction of vibration and acoustic noise," IEEE Trans. Industry Electronics, 2004, 51(2): 374-380.

[14] Lin F, Yang S. "An approach to producing controlled radial force in a switched reluctance motor," IEEE Trans. Industry Electronics, 2007, 54(4): 2137-2146.

[15] Liu X, Zhu Z Q. "Electromagnetic performance of novel variable flux reluctance machines with DC-field coil in stator,' IEEE Trans. Magnetics, 2013, 49(2): 3020-3028.

[16] Liu X, Zhu Z Q. "Comparative study of novel variable flux reluctance machines with doubly fed doubly salient machines," IEEE Trans. Magnetics, 2013, 49(7): 3838-3841.

[17] Cameron D E, Lang J H, Umans S D. " The origin and reduction of acoustic noise in doubly salient variable reluctance motor," IEEE Trans. Industry Applications, 1992, 26(6): 12501255.

[18] Long S A, Zhu Z Q, Howe D. "Vibration behaviour of stators of switched reluctance motors," IEE Proc. Electr. Power Appl., 2001, 148(3): 257-264.

[19] Pollock C, Wu C Y. "Acoustic noise cancellation techniques for switched reluctance drives," IEEE Trans. Industry Applications, 1997, 33(2): 477-484.

[20]Wang Xiuhe. Permanent magnet motors[M] . Beijing : Press of Electric Power, 2007 : 52-54.

[21] Kim K T, Kim K S, Hwang S M, et al. "Comparison of magnetic forces for IPM and SPM motor with rotor eccentricity,"IEEE Transactions on Magnetics, 2006, 37(5) : 3448-3451.

[22] Henneberger G, Sattler P K, Hadrys W, et al. "Procedure for the numerical computation of mechanical vibrations in electrical

Machines," IEEE Transactions on Magnetics , 1992, 28(2) :

1351-1354 